\title{
Violent Victimization against Women in Canada: Evidence from the General Social Survey 2009 Data, a Gendered Study
}

\author{
Adisah-Atta Isaac \\ Department of Political Studies, University of Saskatchewan, Saskatoon, Canada \\ Email: iaa408@mial.usask.ca
}

How to cite this paper: Isaac, A.-A. (2017) Violent Victimization against Women in Canada: Evidence from the General Social Survey 2009 Data, a Gendered Study. Open Journal of Social Sciences, 5, 38-50. https://doi.org/10.4236/jss.2017.54004

Received: February 27, 2017

Accepted: April 14, 2017

Published: April 17, 2017

Copyright $\odot 2017$ by author and Scientific Research Publishing Inc. This work is licensed under the Creative Commons Attribution International License (CC BY 4.0).

http://creativecommons.org/licenses/by/4.0/

\begin{abstract}
This study aimed to examine victimization against women in Canada. Statistics Canada General Social Survey (GSS) 2009 data set was used in this current study for the analysis. In all, 31,510 household were surveyed and out of that, 19,500 responses representing $61.6 \%$ were obtained for the GSS 2009, a sample which was smaller than the 24000 which was used for the 2004 general social survey. In this study, the short version of the GSS 2009 which has a sample of 1512 was used for the analysis. At the end of the study, it was revealed that there is no statistically significant difference regarding the experience of victimization in both males and females in Canada ( $\mathrm{p}$-value $=0.418$, Lambda $=0.003, \mathrm{Phi}=0.21$, Cramer's $\mathrm{V}=0.21$. However, the results of the study revealed a significant difference the impacts of victimization of males and females respectively. Thus women are more likely to experience depression after being victimized than men ( $p$-value $=0.000)$. Finally outcome of the study showed that respondents living in Urban neighborhoods were more likely to experience violent victimization than those in rural communities (Lambda $=$ 0.000 , Phi $=0.106$, Cramer's V $=0.106$ and p-value $=0.000$ ). The study therefore recommends that policies and programs to address violence against women need to be sustainable, properly financed, and parcipatory-involving not only women but men. Also comprehensive victim support systems are essential, ecompassing legal and counseling since the study indicated women experience more of the negative impacts after being victimized.
\end{abstract}

\section{Keywords}

Violent Victimization, Gender, Psychological Impacts

\section{Introduction}

Violent victimization has been viewed to have serious impact on the well-being 
of victims, their families, friends, their community and the society at large [1]. It's important to note that, this consequence can be in a form of financial, physical, psychological as well as emotional.

Gender based victimization has been recognized, most particularly violence victimization against women at the national level and international levels. This has been viewed as a serious and ongoing obstacle to gender equality and women's human rights and their fundamental freedoms [2]. It is worthy to note that, by understanding and appreciating the various dimensions of this global problem through research, decision makers would be able to better develop and evaluate measures and design strategies to prevent and eliminate victimization against any group most importantly against women.

In 2000, the Federal/Provincial/Territorial Ministers responsible for status of women commissioned statistics Canada to develop a set of statistical indicators on violence against women with the purpose of establishing a standard for monitoring changes over time and highlighting emerging issues. These indicators were first printed in a report titled "Assessing violence against women: A statistical profile (2002)". This report was updated in 2006 using the 2006 General Social Survey data. The 2009 General Social Survey on victimization which was meant to update the 2006 report has however been direct towards victimization of the aged. Studies that have used the 2009 General Social Survey for gender related studies have either focused on the Territories or on Aboriginal women. Using the 2009 General Social Survey, this current study seeks to examine violence victimization from gender perspective in General. This paper specifically examines the impact of violence victimization committed against women using evidence from the general social survey data set. It will further examine how the different gender orientation is affected by violent victimization.

\section{Literature Review}

\subsection{Theoretical Framework}

Lifestyle-Exposure Theories of Victimization: Hindelang, Gottfredson, and Garofalo [3] developed one of the systematic theories of violence victimization called the lifestyle-exposure approach. Primarily, the theory sought to account for the differences in the risk of violent victimization across social groups even though it has been extended to included property crime and it forms. The researcher adopts the lifestyle-exposure theory for the study. The purpose of this adoption is to empirically test the basic assumption underpinning this theory. According to the life-exposure theory, the lifestyles of individuals (which is socio-culturally determined) demographically, has the propensity of increasing or decreasing an individual's venerability to criminal victimization. To them, both ascribed and achieved status characteristics which includes but not limited to age, gender, race, income, marital status are important links of voracious crime because these status attributes bring with themselves some shared expectations about how, when and what behavior one should demonstrate across. And this in effect enables or constraints the tendency of risking crime experience. 
Illustratively, the process of gender stereotyping in many societies has resulted in many gender differences. Thus, the type of basic activities (i.e. where and with whom time is spent) the degree of supervision in daily activities, the likelihood of having contact with strangers, and exposure to risky and dangerous public places. Therefore, according to the Life-exposure theory, because females spend most of the time home due to supervisory, house-keeping and child-rearing responsibilities, they are more likely to be shielded from crime victimization than males who have fewer restrictions on their daily lives, and spend more time away from a protective home environment. In simple terms, gender differences in traditional lifestyles are said partly to explain the higher victimization risks of men than women. Nonetheless, considerable number of studies for example [4] [5] [6] have concluded that women are more exposed to crime victimization than men-a direct variance with the central assumption underpinning the theory. It is for this reason that using the General Social Survey 2009 data, the study sought to empirically investigate the validity of the life-exposure theory in the light of violent victimization against women in Canada.

\subsection{Gender and Place of Residence as a Risk Factor of Violent Victimization}

Majority of violent victimization researchers for example [4] [7] [8] have found out that being a female is the main factor of violent victimization. Similar studies have revealed that women are more significantly likely to experience violent victimization than men [9] [10]. In consistent with the study above, Tjaden and Allison conducted a study to determine whether gender correlates with post-separation violence. This study was conducted in the United States within the periods of November 1995 and May 1996. In all 8000 men and women were selected for the study. The outcome of the study showed the more women than men reported experience violence victimization before and after relationship ended with their partner [11]. Even though gender is a strong risk for violence victimization, many theories have found that certain groups of people are at higher risk for violent victimization than other factors even though gender moderates these effects.

Several studies have also established a positive correlation between rural versus urban living and violent victimization [12]. In addition, De Keseredy and Schwartz [6] revealed in their study that rural living was more related to the occurrence of violence victimization signifying that patriarchy is heightened in these areas.

While some of the limited existing literature indicates that there are no conclusive numbers regarding the incidence of violent victimization in rural and urban Canada [13], Statistics Canada has found that rates of violent victimization in rural areas may be similar to those in urban areas [14] [15]. Most importantly Northcott noted that the total combined rate of domestic violence (in rural and urban areas) in Canada increased between 2006 and 2008. The rates of domestic violence perpetrated by both spouses/former spouses and family 
members were higher in rural areas than in urban areas. In urban areas, the rates of overall domestic violence perpetrated by both spouses/former spouses and family members also fluctuated, but with a decrease between 2006 and 2007, followed by an increase in 2008 [16]. This implies that there is no consensus in literature as to whether people who live in rural communities experience less victimization than people in live in urban areas and vice versa.

\subsection{Impacts of Violent Victimization on Males and Females}

Violent victimization has been recognized as a public policy issue as well as a social justice issue and as such several studies have been directed towards this regard. Several studies and analysis have explored and differentiated the issue of men's and women's experiences of violent victimization [17] [18] [19]. These studies have shown that women experience significantly higher rates of severe and dangerous violence victimization such as being beaten up, being choked, being strangled, suffocated, assaulted with weapon or sexually as well as death and injuries. In addition, Gadd et al have also revealed that women are most likely to experience repeat victimization in a form of threat, intimidation and assaults [20].

Evidence from studies such as Johnson and Bunge indicates that women experience more negative of violent victimization than men including emotional/psychological, stress, anxiety, depression, lowered self-esteem, sleeping problems, post-traumatic stress and amongst others [21]. Other studies show that often when examining violent victimization, men and women report being victims to an equal extent [22].

In the lens of the national intimate partner and sexual violence survey (NISVS) 2010 Summary Report from the National Center for Injury Prevention and Control, almost one-third of women from the United States have been violently victimized. The survey revealed that these women had experienced being physically assaulted with consequences such as injury, sleeping disorder, depression, expressing anger and amongst others [23]. Black et al further reported that, one-quarter of the women they sampled for the study thus (25.7\%) were being fearful and more than one out of five women were concerned about their safety as well as one out of five reported post-traumatic stress disorder for the reason of being violently victimize.

Augustine et al in their study also recognized psychological coercion and degradation are some of the negative outcomes that accompanies such violent act against women. They further argued that emotional disorders are long lasting as well as post-traumatic stress disorder is significantly higher for women who have been violently victimize [24]. Sinha [25] in his study on titled measuring victimization against women: statistical trend, revealed that women who had experienced violent victimization had their daily stress level being elevated within the first twelve-month aftermath of being victimize. Overall, Sinha noted (53\%) of women victimized by spouse indicated that they had most of their days quite a bit or extremely stressful significantly higher than women not victimize. It has 
also been revealed that experiences of violent crime also significantly impact women's mental health as well as their emotional wellbeing. For example, according to the Statistical Canada [1] women who have been victimize by their spouse were seven times more likely to be fearful than male victims, three times likely to be depressed or anxious and twice to be angry although men and women were equally likely to be angry about non-spousal violent incidents. Evidence from the above literature reviewed shows that females suffer the most as far violent victimization is concern.

\subsection{Hypotheses}

$\mathrm{H}_{1}$ : Women are more likely to report experiencing victimization their men counterparts

$\mathrm{H}_{2}$ : Women who are victims of violence are more likely to experience emotional and Psychological consequences than men.

$\mathrm{H}_{3}$ : Respondents who live in urban neighborhoods are more likely to report experiencing victimization than are those who live in rural neighborhoods

\section{Methodology}

\subsection{Dataset}

Statistics Canada's 2009 General Social Survey (GSS) accessible at http://www.healeystatistics2e.nelson.com/student/book/Data_Sets/datasets.html was used in this current study for the analysis. In 2009, Statistics Canada conducted the General Social Survey on victimization for the fifth time. The previous surveys on victimization were conducted in 1988, 1993, 1999 and 2004. The General Social Survey is specifically designed to gather information on the social trends in society in order to monitor social change as well as to gather information that can help shape social policy in Canada (Statistics Canada. Study. 2009) [1]. Thus, the survey was undertaken to firstly provide evaluations of $\mathrm{Ca}$ nadian's Individual experiences of eight offences type, secondly to examine the risk factors associated with victimization, thirdly to examine the reporting rates to police. It was also conducted to measure the nature and extent of spousal violence, measure fear of crime and examine public perceptions of crime and the criminal justice system in particular. The target population of the 2009 General Social Survey (GSS) comprised all persons 15 years and older in the 10 provinces of Canada excluding full time residents of institutions.

Data collection for the GSS 2009 took place from February to November inclusive. The respondents for the survey were spread evenly to cover ten months to characterize seasonal variation of information. One interview was conducted within 45 minutes and prior to the data collection, the questions were pilot tested. In all, out of the 31,510 households that were selected, 19,500 responses representing 61.6\% were obtained for the GSS 2009, a sample which was smaller than the 24000 which was used for the 2004 survey. In this study, the short version of the GSS 2009 which has a sample of 1512 was used for the analysis. In this study, 'non-response' would be categorized as those who refused participa- 
tion, could not be reached, or could not speak English or French. Responses were weighted by the researcher to represent the non-institutionalized Canadian population aged 15 years or over, in the 10 provinces.

\subsection{Measurement}

Overall, the General Social Survey 2009 measures three types of self-reported victimization (sexual assault, robbery and physical assault. The general social survey also measures four types of self-reported household victimization (break and enter, motor vehicle theft, household theft and vandalism). These incidents are referred to as "household victimization" as the target of the incident is the household, rather than an individual person.

\subsection{Independent Variables: Gender and Place of Residence}

For the purpose of this study, Gender and place of residence will be used as the independent variables. In the dataset, gender was coded as ( $1=$ male, $2=$ female $)$ and residence coded as ( $1=$ Rural, $2=$ Urban). Several studies for example [4] [11] have used gender as their independent variable to predict whether males or females experiences greatly the trauma of victimization whiles studies have also established a positive correlation between rural versus urban living and violent victimization [6].

\subsection{Dependent Variables: Consequences of Violent Victimization, Violent Victimization}

For the purpose of this study and being consistent with previous studies conducted on victimization for example Augustine et al and Sinha, psychological coercion and degradation, stress and amongst other are some of the negative outcomes that accompanies violent victimization. In order to measure the impacts of violent victimization, the following question will be used: "Taken medication for depression? The responses were coded $(1=$ Yes, $2=$ No). These measures are in consistence with Augustine et al and Sinha who examined how violent victimization affects the individual.

Also, violent victimization defined in this study includes but not limited to acts of physical assault (being pushed, grabbed, being slapped, being choked, having something thrown at that can hurt, being hit with something that could hurt, being threatened with or having knife or gun used, being kicked, bit, physically threatened, or doing anything that could hurt) and sexual assault (being forced into any sexual activity by being threatened, held down, or hurt in some way).

In order to measure whether a person have experience some of the abovementioned forms of victimization, one question was asked: "Have you ever been a victim of crime in your life time"? The responses were coded ( $1=$ Yes, 2 $=$ No).

\section{Analysis and Interpretations of Findings}

This section presents the analysis and the discussions of the results of the data 
acquired from the participants of the study. The study looked at impacts of violent victimization against women in Canada and used evidence from the GSS 2009 data as the case for the study. Three hypotheses were generated for the study and this section deals with the testing of the hypotheses and the discussions of the study.

\subsection{Descriptive Statistics}

From the analysis of the questionnaire data collected from the participants of the study, it was observed that $49.5 \%$ of the participants were males whilst $50.5 \%$ of them were also females. This shows that both gender was well represented in the study and that the difference between them is not that much. This is represented in Table 1 below.

From Table 1, it can also be observed that 1211 (80.1\%) constituting the greater majority of the respondents were urban dwellers whiles 301 (19.9\%) were rural dwellers. Also, regarding having experienced victimization in lifetime, 944 $(62.4 \%)$, thus greater majority were of the view that they have been a victim of violence in one way or the other while $568(37.6 \%)$ also responded that they have not experience any form of victimization in their life time.

\subsection{Testing of Hypotheses}

\subsubsection{Hypothesis 1}

$\mathrm{H}_{1}$ : Women are more likely to report experiencing victimization their men.

In the "Yes" row, which represent the percentage of men and women who have experienced violent victimization, we can see for example that $474(50.3 \%)$

Table 1. Descriptive statistics of the data.

\begin{tabular}{ccc}
\hline \multicolumn{2}{c}{ Sex of Respondents } \\
\hline Frequency & Valid Percent (\%) \\
Male & 747 & 49.5 \\
Female & 765 & 50.5 \\
Total & 1512 & 100 \\
\hline \multicolumn{3}{c}{ Urban/Rural indicator } \\
\hline Urban & 1211 & 80.1 \\
Rural & 301 & 19.9 \\
Total & 1512 & 100 \\
\hline \multicolumn{3}{c}{ Ever been a victim of crime-lifetime } \\
\hline Yes & 944 & 62.4 \\
No & 568 & 37.6 \\
Total & 1512 & 100 \\
\hline Tes & 107 & 7.1 \\
No & 1405 & 92.1 \\
Total & 1512 & 100 \\
\hline
\end{tabular}

Source: General Social Survey, 2009, Canada. 
of men have experienced violent victimization whiles 470 (49.7\%) of women have also experienced victimization. This shows a similar favorable response from both men and women regarding the experience of victimization.

The value for the Phi and Cramer's V is 0.21 respectively which suggest that there is a relatively weak association between gender and the experience of victimization. This is also supported by the $\mathrm{P}$ value $<0.05$ of 0.418 signifying no relationship. The value for the Lambda is also 0.03 which suggest very weak relationship but it must be noted that Lambda tends to underestimate while Cramer's $\mathrm{V}$ turns to overestimate. Taken together, the differences in the column percentages in the Table 2 shows no substantial differences regarding the males and females experiencing violent victimization. It is also supported by the $\mathrm{P}$ value $<0.05$ of 0.418 as well as the lambda 0.03 , phi 0.21 and crema's V 0.21 respectively. This indicates that the null hypothesis that states there is no relationship between gender and the experience of victimization has been supported while the alternative hypothesis stating women are more likely to report experiencing victimization than men has been rejected.

\subsubsection{Hypothesis 2}

$\mathrm{H}_{2}$ : Women who are victims of violence are more likely to experience emotional consequences than men who are victims.

From Tables 3-5, it can be observed that there is a substantial difference

Table 2. The significant relationship between victimization and gender (Percentages).

\begin{tabular}{|c|c|c|c|c|}
\hline & & \multicolumn{2}{|c|}{ Sex of respondent. } & \multirow{2}{*}{ Total } \\
\hline & & Men & Women & \\
\hline \multirow{2}{*}{ Ever been a victim of crime-lifetime } & Yes & $474(50.3 \%)$ & $470(49.7 \%)$ & 944 \\
\hline & No & $273(48.1 \%)$ & $295(52 \%)$ & 568 \\
\hline \multirow[t]{3}{*}{ Total } & & 747 & 765 & 1512 \\
\hline & \multicolumn{3}{|c|}{ Chi-Square Tests } & \\
\hline & Value & Df & P-value & \\
\hline Pearson Chi-Square & 0.655 & 1 & 0.418 & \\
\hline
\end{tabular}

Note: Weighted Data; All chi-square tests are significant at p-value $<0.05$; Source: General Social Survey 2009, Canada; Lambda $=0.003, \mathrm{Phi}=0.21$, Cramer's V $=0.21, \mathrm{P}=0.418, \mathrm{~N}=1512$.

Table 3. Ever been a victim of crime-lifetime * Take Medication for Depression Crosstabulation.

\begin{tabular}{|c|c|c|c|}
\hline \multicolumn{4}{|c|}{ Ever been a victim of crime-lifetime } \\
\hline & Yes & No & Total \\
\hline \multicolumn{4}{|l|}{ Take medication for } \\
\hline depression & $85(9.0 \%)$ & $22(3.9 \%)$ & 107 \\
\hline \multicolumn{4}{|l|}{ Yes } \\
\hline No & $859(91.0 \%)$ & $546(96.1 \%)$ & 1405 \\
\hline \multirow[t]{3}{*}{ Total } & 944 & 568 & 1512 \\
\hline & \multicolumn{2}{|c|}{ Chi-Square Tests } & \\
\hline & Value & Df & P-value \\
\hline Pearson Chi-Square & $14.198^{\mathrm{a}}$ & 1 & 0.000 \\
\hline
\end{tabular}

Lambda $=000$, Phi $=0.097$, Cramer's V $=0.097$. 
Table 4. Control for Gender: Take medication for depression $\star$ Ever been a victim of crime-lifetime $*$ Sex of respondent. Cross tabulation (Percentages).

\begin{tabular}{|c|c|c|c|c|c|}
\hline \multirow{2}{*}{$\begin{array}{l}\text { Sex of } \\
\text { respondent. }\end{array}$} & & & \multicolumn{2}{|c|}{ Ever been a victim of crime-lifetime } & \multirow{2}{*}{ Total } \\
\hline & & & Yes & No & \\
\hline \multirow{3}{*}{ Male } & Take medication & Yes & $26(74 \%)$ & $9(25.7 \%)$ & 35 \\
\hline & for depression & No & $448(63 \%)$ & $263(37 \%)$ & 711 \\
\hline & Total & & 474 & 272 & 746 \\
\hline \multirow{3}{*}{ Female } & Take medication & Yes & $59(82 \%)$ & $13(18 \%)$ & 72 \\
\hline & for depression & No & $411(59 \%)$ & $282(41 \%)$ & 693 \\
\hline & Total & & 470 & 295 & 765 \\
\hline \multirow{3}{*}{ Total } & Take medication & Yes & $85(79 \%)$ & $22(21 \%)$ & 107 \\
\hline & for depression & No & $859(61 \%)$ & $545(39)$ & 1404 \\
\hline & Total & & 944 & 567 & 1511 \\
\hline
\end{tabular}

Table 5. Measures of Association for the controlled variables.

\begin{tabular}{ccccccc}
\hline & Lambda & Phi(Value) & $\begin{array}{c}\text { (Approx } \\
\text { Sig, Phi) }\end{array}$ & $\begin{array}{c}\text { Cramer's } \\
\text { V(value) }\end{array}$ & $\begin{array}{c}\text { (Approx } \\
\text { Sig, V) }\end{array}$ & P-value \\
\hline Full Sample & 0.000 & 0.097 & 0.000 & 0.097 & 0.000 & 0.000 \\
Male & 0.000 & 0.050 & 0.176 & 0.050 & 0.176 & 0.119 \\
Female & 0.000 & 0.136 & 0.000 & 0.136 & 0.000 & 0.000 \\
\hline
\end{tabular}

Note: Weighted Data, all chi-square tests are significant at p-value $<0.05$; Source: General Social Survey 2009, Canada.

between the opinions of mem and women on the issue of the impact of violent victimization when gender was controlled.

The value for the Phi and Cramer's V is 0.097 which suggest a moderate relationship which is also supported by the $\mathrm{p}$ value $<0.05$ of 0.000 signifying a strong relationship. The value of lambda for this table is therefore 000. Lambda has, in other words, failed to capture the substantial difference shown in the table but it must be noted that Lambda tends to underestimate while Cramer's V tends to overestimate.

From Tables 3-5, when gender was controlled, there was no statistically significant changes regarding men thus $p$-value (male) $=0.119$, however, there was a statistical significant between victimization and depression as far as women were concerned, P-value (female) $=0.000$. it can therefore be concluded that this hypothesis that states women who are victims of violence are more likely to experience emotional consequences than men has been supported.

\subsubsection{Hypothesis 3}

$\mathrm{H}_{3}$ : Respondents who live in urban neighborhoods are more likely to report experiencing victimization than are those who live in rural neighborhoods.

Comparing the row and column-numbers for the cells in the Table 6, it can be observed the there is a remarkable difference. The column-number in the rows 
Table 6. The relationship between victimization and residence (Rural/Urban) of respondent (in Percentage).

\begin{tabular}{ccccr}
\hline & & \multicolumn{2}{c}{ Ever been a victim of crime-lifetime } & \multirow{2}{*}{ Total } \\
\cline { 3 - 4 } & & Yes & No & \\
\hline Urban/Rural indicator. & Urban & $787(65 \%)$ & $424(25 \%)$ & 1211 \\
& Rural & $157(52.2 \%)$ & $114(47.8 \%)$ & 301 \\
Total & & 944 & 538 & 1512 \\
& & Chi-Square Tests & & \\
& Value & Df & P-value & \\
Pearson Chi-Square & $16.915^{\mathrm{a}}$ & 1 & .000 & \\
\hline
\end{tabular}

Note: Weighted Data, all chi-square tests are significant at p-value $<0.05$; Source: General Social Survey 2009, Canada. Lambda $=0.000, \mathrm{Phi}=0.106$, Cramer's V =0.106, $\mathrm{p}=0.000 ., \mathrm{N}=1512$.

are 787 (52\%) and 157 (10.4\%). This indicates that respondents that respondents who live in urban areas are more likely to be victimized than those who live in rural areas.

The value for the Phi and Cramer's V is 0.106 which suggest a strong relationship which is also supported by the $\mathrm{p}$ value $<0.05$ of 0.000 signifying a strong relationship. The value for the Lambda is also 0.000 which suggest no relationship but it must be noted that Lambda tends to underestimate while Cramer's $\mathrm{V}$ tends to overestimate. From the observation, above, it can be deduced that people living in urban neighborhoods are more prone to victimization than people who live in rural neighborhoods.

\subsection{Discussion of Results}

Several studies on this subject under investigation have reported that women are more likely to experience violent victimization than men. This has been found repeatedly throughout several research [2] [6]. However, from the Table 2 the analysis above, the current analysis revealed that gender was not significantly related to violent victimization. Research shows that often when examining violent victimization, men and women report being victims to an equal extent [22]. The current study's findings support this claim with regard to the above studies, however rejects the position of the life exposure theory that indicates that the higher victimization risks of men than women.

From the analysis of data presented in Table 2, it can be observed that most of the respondents who experienced psychological and emotional disturbances as a result of victimization were women respondents. This meant that females experience more negative consequences as a result if victimization than mem. This is supported by a number of studies for example [23] [24] [25], who found similar results in their study.

Finally regarding rural/urban divide, it must be noted that existing literature indicates that there are no conclusive evidence regarding the incidence of violent victimization in rural and urban divide [13]. Other studies have also found that 
rates of violent victimization in rural areas may be similar to those in urban areas [14] [15]. Even though the above literature suggests no conclusive evidence, this current study revealed that people living in Urban communities experience violent victimization than those in rural communities. In this current study, I attribute this great differences to the deficiencies found in the data set. It must be noted that in the data set that was used greater majority $1211(80.1 \%)$ were from urban communities while 301 (19.9\%) were from rural communities. This might account for the differences seen in the findings of this study.

\section{Conclusions}

This research was envisioned to further our understanding of the multifaceted, gendered scopes of violence in all its forms and how women's experiences of violence interconnect with other aspects of their lives. It must be noted that the findings of the study did not reveal any statistically significant difference regarding men and women in terms of their experience of violent victimization. This implies that both males and females are at risk of experiencing violent victimization. Also, the findings of this study revealed a statistically significant difference regarding the impact of violent victimization of men and women. The findings revealed that women were more likely to experience negative impact of violent victimization for example depression than men.

Finally, the study also revealed that residents living in urban communities were more prone to violent victimization than people living in rural communities. However, the differences were not statistically strong since existing literature indicates that there is no conclusive evidence regarding the incidence of violent victimization in rural and urban communities.

In this regard, this paper is proposed to support policy and program development and decision making for governments, NGO's, service providers, academicians, researchers and all others working to eliminate all forms of violence against women and girls since the study revealed that they experience more negative impact after they experience victimization. The researcher is therefore confident that as this body of knowledge continues to advance, it will promote prevention efforts and enhance responses to women and girls who experience violence in our communities.

The main limitations of using the 2009 General Social Survey Data has to do with the variables that were included and their capacity to explain contextual elements of victimization. For example, the current study is unable to examine the circumstances in which gender impact victimization. The researchers found that in some circumstances the women's partners would threaten to hurt the children if the women did not perform sexual acts. These threats of violence would often come to fruition, resulting in women being sexually victimized. Future research should perform qualitative interviews with mothers who have experienced violent victimization especially from their husbands. There are also limitations in terms of how violent victimization was measured. The independent variables were measured contemporarily, whereas the dependent variables 
captured past experiences. Thus, this inconsistency makes causal interpretation impossible.

In addition, the data set did not measure background conditions surrounding the victimization. For example, a question that measured victimization asked respondents if they had ever experienced victimization in life time. This does not measure important factors such as period, regularity, or severity of victimization.

Therefore, future research should employ improved measures of violent victimization, including: brutality of injury or victimization, regularity of occurrence, and time of abuse.

There are also limitations in terms of how the impact of violent victimization was measured. For instance, the question that measured whether the respondents have experienced any psychological impact due to being victimize was: taken medication for depression. It must be noted that depression is not the only psychological impact the victims of crimes face. For example, evidence from studies such as Johnson and Bunge, Sunders indicates people who suffer from violent victimization experiences emotional/psychological problems such stress, anxiety, lowered self-esteem, sleeping problems, post-traumatic stress and amongst others. Therefore, future studies should measure variables such as anxiety, disappointment, lower self-esteem, sleeping problems, confusion, and frustration in addition to depression. In this regard the full impact can be measured.

In summary, I propose that strategies and programmes to tackle violence against women need to be sustainable, appropriately financed and participatory-thus including not only women but men. Also, comprehensive victim support systems which include hotlines, shelters, health services, legal support, counseling and economic empowerment are also essential to eradicate victims against women in Canada. Finally, I would like to mention that continues developments and support for data collection are required to assess changes over time and advancement towards a Canada free from violence against women in all its forms.

\section{References}

[1] Justice Canada (2013) Victims' Rights: Enhancing Criminal Responses to Better Meet the Needs of Victims of Crime in Canada. Consultation on Victims Bill of Rights, Discussion Paper.

[2] United Nations, General Assembly (1993) Declaration on the Elimination of Violence against Women. A/RES/48/104.

[3] Hindelang, M.J. (1978) Race and Involvement in Common Law Personal Crimes. American Sociological Review, 43, 93-109. https://doi.org/10.2307/2094764

[4] Brownridge, D.A. (2009) Cohabitation, Marriage, and Men's Intimate Partner Violence Victimization. The Open Criminology Journal, 2, 10-17. https://doi.org/10.2174/1874917800902010010

[5] Katz, J., May, P., Sörensen, S. and Del Tosta, J. (2010) Sexual Revictimization during Women's First Year of College: Self-Blame and Sexual Refusal Assertiveness as Possible Mechanisms. Journal of Interpersonal Violence, 25, 2113-2126. https://doi.org/10.1177/0886260509354515

[6] De Keseredy, W.S. and Schwartz, M.D. (2009) Dangerous Exits. Rutgers University Press, New Jersey. 
[7] Tyler, K.A., Brownridge, D.A. and Melander, L.A. (2011) The Effect of Poor Parenting on Male and Female Dating Violence Perpetration and Victimization. $V i$ olence and Victims, 26, 218-230.

[8] Clements-Nolle, K., Marx, R. and Katz, M. (2006) Attempted Suicide among Transgender Persons: The Influence of Gender-Based Discrimination and Victimization. Journal of Homosexuality, 51, 53-69. https://doi.org/10.1300/J082v51n03_04

[9] Spiwak, R. and Brownridge, D.A. (2005) Separate Women's Risk for Violence. Journal of Divorce and Remarriage, 43, 105-117. https://doi.org/10.1300/J087v43n03_06

[10] Brownridge, D.A. (2006) Violence against Women Post-Separation. Aggression and Violent Behavior, 11, 514-530.

[11] Tjaden, P., Thoennes, N. and Allison, C.J. (2000) Comparing Stalking Victimization from Legal and Victim Perspectives. Violence and Victims, 15, 7-22.

[12] Brownridge, D.A. (2003) Male Partner Violence against Aboriginal Women in Canada: An Empirical Analysis. Journal of Interpersonal Violence, 18, 65-83. https://doi.org/10.1177/0886260502238541

[13] Brookbank, C. (1995) Spouse Abuse in Rural Communities: A Review of the Literature. Department of Justice Canada.

[14] Gannon, M. and Mihorean, K. (2005) Criminal Victimization in Canada, 2004. Canadian Centre for Justice Statistics, Ottawa.

[15] Bunge, V.P. and Levett, A. (1998) Family Violence in Canada: A Statistical Profile. Statistics Canada, Ottawa.

[16] Northcott, M. (2013) A Survey of Survivors of Sexual Violence. WE ALL HAVE A ROLE, 12 .

[17] Kimmel, M.S. (2002) "Gender Symmetry" in Domestic Violence: A Substantive and Methodological Research Review. Violence against Women, 8, 1332-1363.

[18] Saunders, D.G. (2002) Are Physical Assaults by Wives and Girlfriends a Major Social Problem? A Review of the Literature. Violence against Women, 8, 1424-1448. https://doi.org/10.1177/107780102237964

[19] Walby, S., Allen, J. and Simmons, J. (2004) Domestic Violence, Sexual Assault and Stalking: Findings from the British Crime Survey. Home Office Research, Development and Statistics Directorate, London.

[20] Farrall, S. and Gadd, D. (2004) Research Note: The Frequency of the Fear of Crime. The British Journal of Criminology, 44, 127-132. https://doi.org/10.1093/bjc/44.1.127

[21] Johnson, H. and Bunge, V.P. (2001) Prevalence and Consequences of Spousal Assault in Canada. Canadian Journal of Criminology, 43, 27-45.

[22] Goldenson, J., Geffner, R., Foster, S.L. and Clipson, C.R. (2007) Female Domestic Violence Offenders: Their Attachment Security, Trauma Symptoms, and Personality Organization. Violence and Victims, 22, 532-545.

[23] Black, M.C., Basile, K.C., Breiding, M.J., Smith, S.G., Walters, M.L., Merrick, M.T., Chen, J. and Stevens, M.R. (2011) The National Intimate Partner and Sexual Violence Survey (NISVS): 2010 Summary Report. National Center for Injury Prevention and Control, Centers for Disease Control and Prevention, Atlanta, GA.

[24] Augustine, M.C., Wilcox, P., Ousey, G.C. and Clayton, R.R. (2002) Opportunity Theory and Adolescent School-Based Victimization. Violence and Victims, 17, 233 253.

[25] Sinha, M. (2013) Measuring Violence against Women: Statistical Trends. Canadian Centre for Justice Statistics, Juristat. 
Submit or recommend next manuscript to SCIRP and we will provide best service for you:

Accepting pre-submission inquiries through Email, Facebook, LinkedIn, Twitter, etc. A wide selection of journals (inclusive of 9 subjects, more than 200 journals)

Providing 24-hour high-quality service

User-friendly online submission system

Fair and swift peer-review system

Efficient typesetting and proofreading procedure

Display of the result of downloads and visits, as well as the number of cited articles Maximum dissemination of your research work

Submit your manuscript at: http://papersubmission.scirp.org/

Or contact jss@scirp.org 